\title{
Tri-Band Parallel Slots Loaded Circular Disk Patch Antenna for C and X-Band Applications
}

\author{
Nagendra P. Yadav
}

School of Electronic Engineering and Optoelectronic Technology, Nanjing University of Science and Technology, Nanjing, China

Email: nagendra1nagendra@gmail.com

Received 27 October 2015; accepted 21 December 2015; published 24 December 2015

Copyright (C) 2016 by author and Scientific Research Publishing Inc.

This work is licensed under the Creative Commons Attribution International License (CC BY).

http://creativecommons.org/licenses/by/4.0/

(c) (†) Open Access

\section{Abstract}

This paper presents the tri-band slot loaded patch antenna for mobile communication. The antenna consists of parallel slots loaded circular disk with defected ground structure antenna (DGS). The antenna without DGS, acts like wide band antenna and bandwidth is $34.45 \%$ (3.47 - $4.92 \mathrm{GHz})$ with maximum gain of $4.97 \mathrm{dBi}$, which can be used in WiMax application. This structure has the following advantages: 1) co-axial feeding technique, which is very simple as compared to other feeding technique, 2) simple and cost effective and 3) it is more efficient than the antenna without DGS. This antenna has been analyzed using IE3D simulation software.

\section{Keywords}

\section{Circular Disk Patch, DGS, Slots Antenna, Tri-Band}

\section{Introduction}

Slot loaded circular disk antennas, with defected ground structure for WLAN, WiMax systems, mobile phone, radar, have been reported by several researchers [1]-[4]. Their work is confined to only single band, double band and wideband, which is not suitable for current market demands. Therefore, in order to overcome the market needs, a multi-band antenna with simple, low cost and solid structure is necessary [5]. Because, multiband antenna will have multi frequencies which can be used in different systems at the same time, the work related to tri-band antenna and multifunction applications have been published by several researchers. The advantage of 
tri-band structure is that, when there is meddling in one band system, the other can still work usually. In 2011, Prasad et al. [6] have reported that circular disk antenna performs well superior than the rectangular microstrip patch antenna. A slot antenna and stacked antenna have many advantages, because of its simple structure, compact [7] such as wider bandwidth and less performer loss [8]-[10]. Recently, Anguera et al. [11] and Cao et al. report that the antenna will better perform when it is incorporated with different bands into stacked patches, cutting slots in the patches [11] [12]. Above presented papers have some drawbacks. Some have low return loss and low gain and some have large size. The large size of antennas is not more valuable in recent communication systems. In the present scenario of wireless communication, the compact and tiny antenna is required. Because it is more useful in different communication schemes at the same time, multiband antenna is mandatory. In this article, a probe-fed tri-band with three parallel slots loaded single layer circular patch antenna has been planned by using defected ground plane. Furthermore, the parallel slots on the circular patch and defected ground plane increase the current path on it and reduce the size of antenna.

Also the concert of the antenna was investigated by the performance of the surface currents on the patch. The sizes of three parallel-slots are selected in such a way so that planned antenna can display triple frequency activities with good matching condition. Without defected ground plane, antenna works like wideband antenna with good gain which is very useful in WiMax applications. The performance of our current design is better than the results published in [13] [14]. The bandwidth of the proposed design is better than [14]. Proposed design is very simple and uses the defected ground plane, which indicates that the proposed design is compact and that the size is reduced as compared to [13] [14]. The co-axial feed technique has been used for the study of the proposed antenna because it occupies less space and has low spurious radiation by using Teflon connector. Details of the antenna are given in next stage.

\section{Antenna Design}

\subsection{Antenna Configuration}

The geometry of a tri-band circular disk patch antenna with (DGS) is depicted in Figure 1. The triple band presentation is achieved by cutting three parallel slots on circular disk patch and rectangular slot on ground plane with a single layer patch. The coaxial probe is directly connected to the patch and FR4 dielectric is used as a substrate, which has dielectric constant of 4.4 and height of dielectric substrate is $1.6 \mathrm{~mm}$. We have selected all the dimensions of proposed antenna, as desirable for triple-band antenna.

\subsection{Design Equation}

Due to the fringing effects, electrically the shining patch of the antenna looks bigger than its physical size; the increment on $L$ is given by:

$$
\Delta L=\frac{0.412 h\left(\varepsilon_{\text {reff }}+0.3\right)\left(W h^{-1}+0.264\right)}{\left[\left(\varepsilon_{\text {reff }}-0.258\right)\left(W h^{-1}+0.8\right)\right]}
$$

where the effective (relative) permittivity is,

$$
\varepsilon_{\text {reff }}=\frac{\varepsilon_{r}+1}{2}+\frac{\varepsilon_{r}-1}{2 \sqrt{1+12 h W^{-1}}}
$$

This is associated to the ratio of $h / W$. The larger value of $h / W$ is, then the smaller effective permittivity is [15] [16]. The effective length of the patch is given by:

$$
L_{\text {eff }}=L+2 \Delta L
$$

The resonant frequency for the $T M_{100}$ mode is:

$$
\begin{gathered}
f_{r}=\frac{1}{\left[2 L_{\text {eff }} \sqrt{\varepsilon_{\text {reff }} \sqrt{\varepsilon_{0} \mu_{0}}}\right]} \\
f_{r}=\frac{1}{\left[2(L+2 \Delta L) \sqrt{\varepsilon_{\text {reff }} \sqrt{\varepsilon_{0} \mu_{0}}}\right]}
\end{gathered}
$$



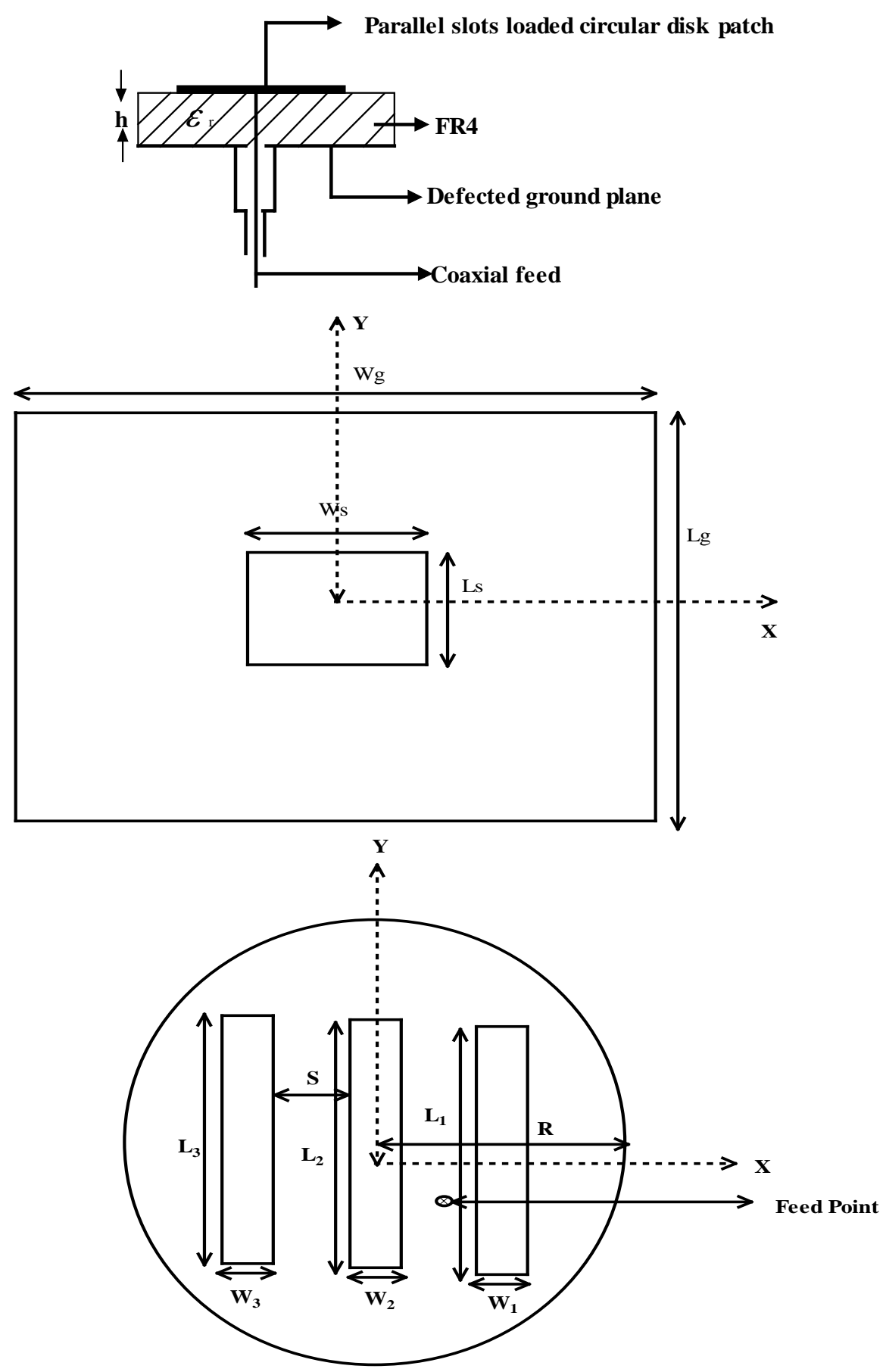

Figure 1. Top view and side view geometry of the proposed triple band antenna.

An optimized width for an efficient radiator is,

$$
W=\frac{1}{\left(2 f_{r} \sqrt{\varepsilon \mu_{0}}\right) \times \sqrt{\frac{2}{\varepsilon_{r}+1}}}
$$

Analysis of circular disk microstrip antenna is same as that of rectangular patch apart from the effective radius and its resonant frequency. Therefore, the analysis of a circular disk patch is carried out by assuming that it is 
equivalent to a rectangular patch [17] in which length $L$ is supposed to be equal to $2 R$ and width $W$ equal to $\frac{\pi R}{2}$ (Figure 1). The value of effective radius $R_{e}$ is considered by equating the area of circular disk to the expanded rectangular patch of dimension $L_{e}$ and $W_{e}$ where $L_{e}$ and $W_{e}$ are calculated by [18]. The design method for original case is given in next step.

\subsection{Design Method}

If the substrate parameter $\left(\varepsilon_{r}, h\right)$ and the operating frequency $\left(f_{r}\right)$ are known then we can easily work out on the size of the patch antenna using above simplified equation following design method to design the antenna:

Step 1: Using Equation (6) to get out the patch width $W$.

Step 2: Calculate the effective permittivity using the Equation (2).

Step 3: Compute the expansion of the length using the Equation (1).

Step 4: Determine the length $L$ by solving the equation for $L$ giving the solution.

From Equation (6), $\left(f_{r}\right)$ is the resonance frequency at which the rectangular/circular microstrip antenna is to be planned. The radiating edge $W$, patch width is typically kept such that it lies within the variety for efficient radiation. By using the above equations we can get the values of concrete length of the patch as:

$$
L=\left[\frac{1}{\left(2 f_{r} \sqrt{\varepsilon_{\text {reff }}} \sqrt{\varepsilon_{0} \mu_{0}}\right)}\right]-2 \Delta L
$$

The final optimized parameters of the antenna are given in Table 1.

\subsection{Working Mechanism and Design Guideline}

Our aim is to design the multiband antenna with the help of parallel slots loaded circular disk patch with (DGS). First, we have designed rectangular ground plane with rectangular slot cut on copper plate. We used the FR4 dielectric on copper plate with thickness of $1.6 \mathrm{~mm}$. After that we stacked a parallel slots loaded circular disk patch with ground plane. With the above idea, the guideline of the design can be shown in four steps, which are given below.

First Step: In first step, by using above formulas, we have design three parallel slots loaded circular disk patch stacked with, without defected ground. We found that the results like broadband antenna with frequency range ( 3.47 - $4.92 \mathrm{GHz}$ ) and central frequency $4.20 \mathrm{GHz}$. The individual bandwidth of the broadband antenna is $34.45 \%$ with maximum gain is $4.97 \mathrm{dBi}$. All results of broadband antenna can be simply shown in Figures 2-4.

Table 1. Optimized dimensions of the antenna (unit: $\mathrm{mm}$ ).

\begin{tabular}{ccc}
\hline Parameter & Value \\
\hline $\mathrm{Lg}$ & 20.0 \\
$\mathrm{Wg}$ & 30.0 \\
$\mathrm{Ls}$ & 8.0 \\
$\mathrm{Ws}$ & 10.0 \\
$\mathrm{R}$ & 10.0 \\
$\mathrm{~L}_{1}, \mathrm{~L}_{2}, \mathrm{~L}_{3}$ & 10.0 \\
$\mathrm{~W}_{1}, \mathrm{~W}_{2}, \mathrm{~W}_{3}$ & 2.0 \\
$\mathrm{~S}$ & 3.0 \\
$\mathrm{FR} 4$ & 4.4 \\
$\mathrm{~h}$ & 1.6 \\
\hline
\end{tabular}




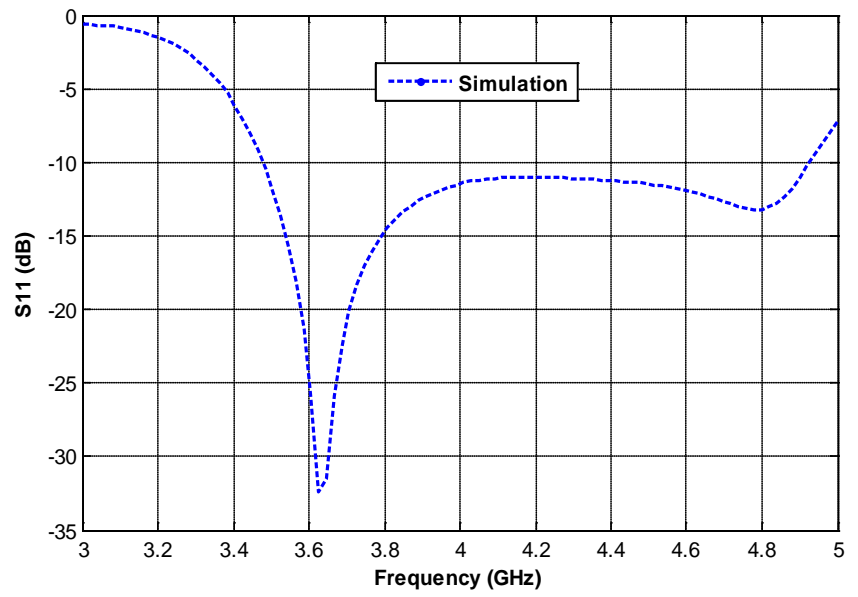

Figure 2. Variation of S11 parameter with frequency of the antenna without defected ground.

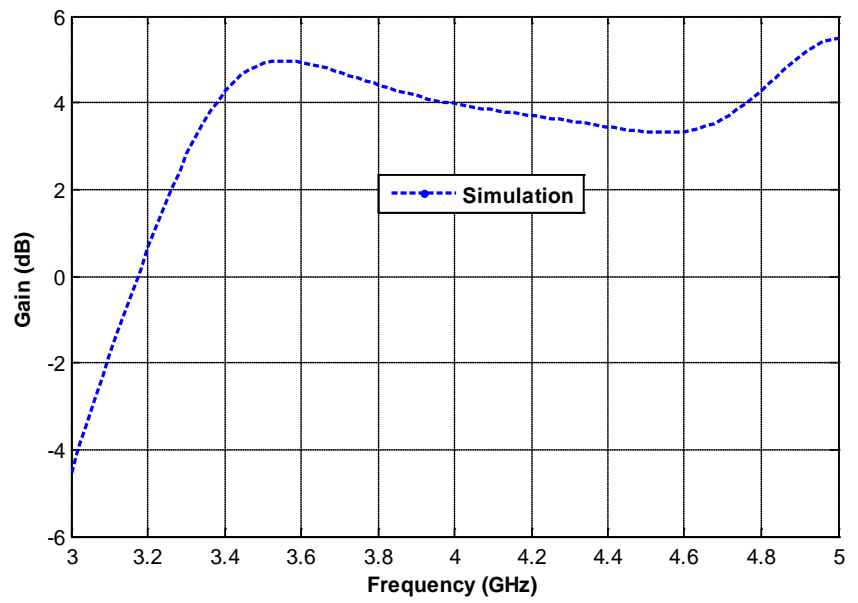

Figure 3. Variation of Gain with frequency of the antenna without defected ground.

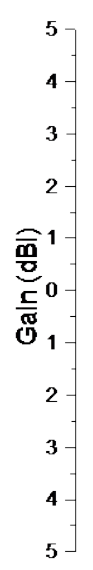

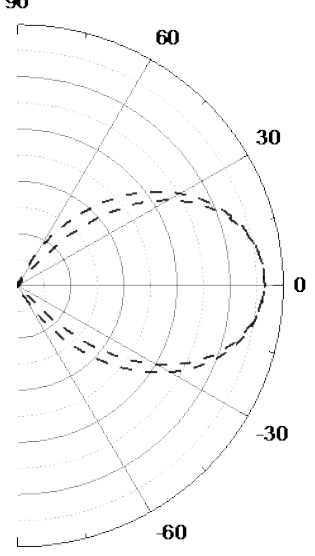

90

Radiation pattern of without defected ground

Figure 4. Radiation patterns of antenna without defected ground plane both $\mathrm{E}$ and $\mathrm{H}$ plane. 
Through calculation and optimization, a broadband three parallel slots loaded disk antenna is achieved as shown in Figures 2-4. The radiation pattern of the broadband antenna is good in both $\mathrm{E}$ and $\mathrm{H}$ plane, which is shown in Figure 4. The dimensions of this broadband design are listed in Table 1.

We have already done more work on broadband antennas, so we are thinking about multiband antenna and then work on the next steps which are given below.

Second step: In second step, we think about the ground defected design, so we cut a rectangular slot on ground plane and stacked circular disk over a defected ground and got the multiband performance, which is my proposed antenna. The dimensions for this proposed design are listed in Table 1 and performances are shown in Figures 5-7.

The Figures 5-7, indicate that the performance of the proposed antenna is tri-band antenna. The variation of $\mathrm{S}_{11}$ parameter with frequency is shown in Figure 5. The triple band antenna can be used in $\mathrm{C}$ and $\mathrm{X}$ band; first two bands in C-band and another last one is used in X-band performance. Similar performance of the gains of the proposed antenna is shown in Figure 6. The radiation pattern of the proposed antenna is shown in Figure 7, in all origin and polar form both the E and H-plane characteristics which is good as compared to published [14]. We have also checked the performance of the antenna with dual and single slot loaded in circular disk patch which is given in next coming steps.

Third step: In third step we used only two parallel slots on circular disk and ground defected is similar as earlier step. The dimensions for this design are listed in Table 1 and performances are shown in Figures 8-10.

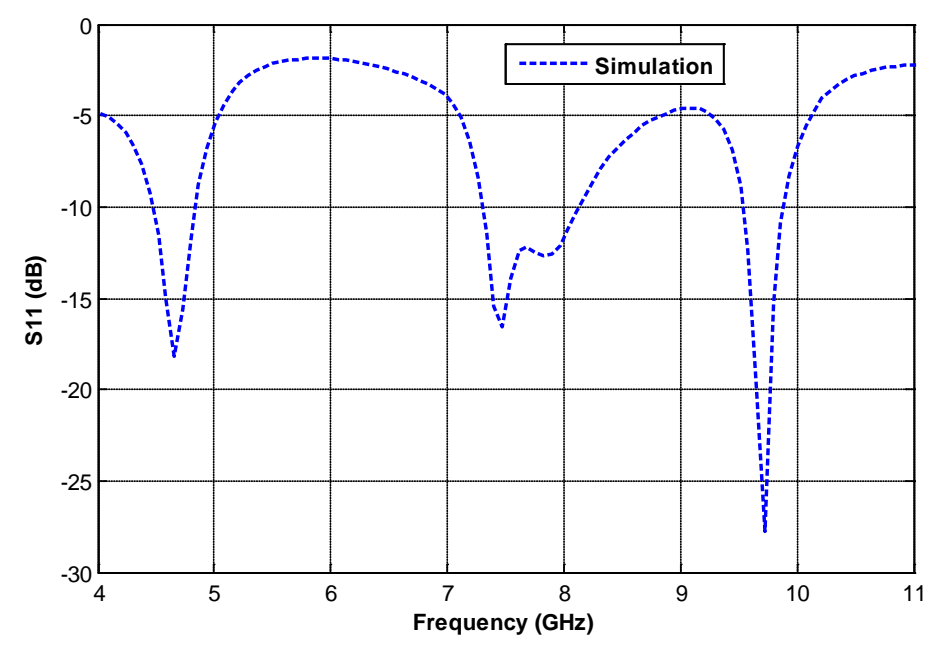

Figure 5. Variation of $S_{11}$ parameter with frequency of the proposed antenna.

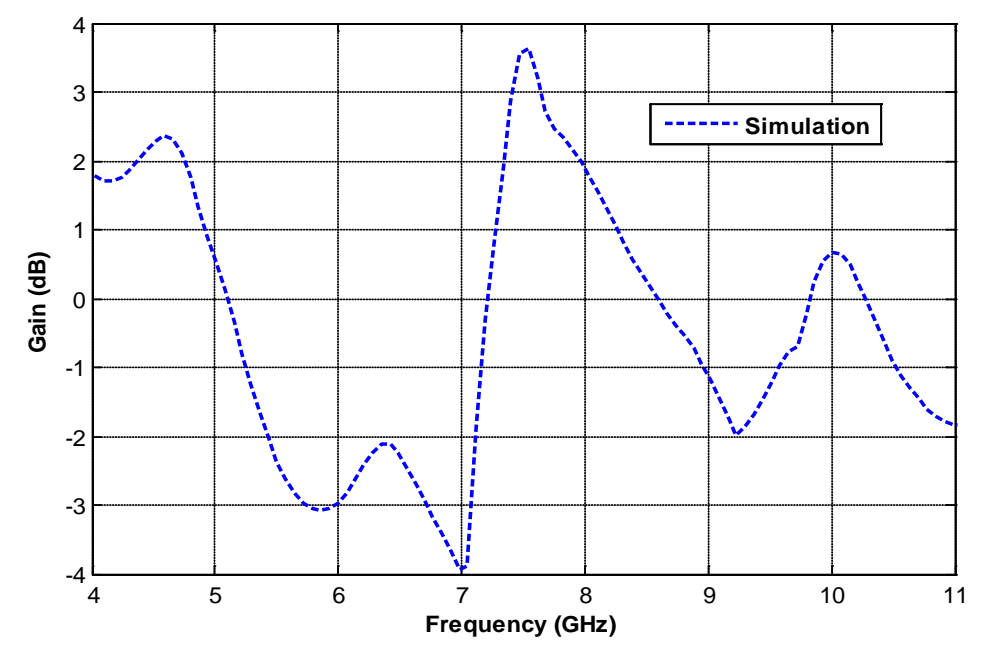

Figure 6. Variation of gain with frequency of the proposed antenna. 


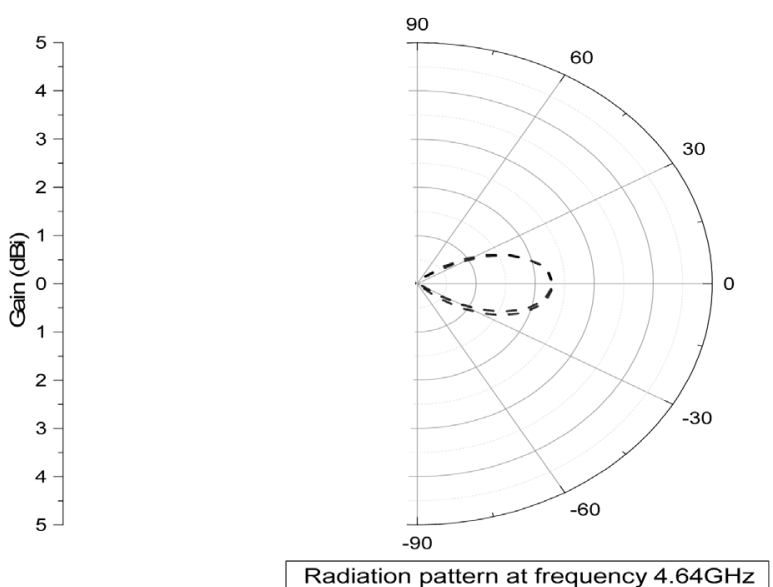

(a)
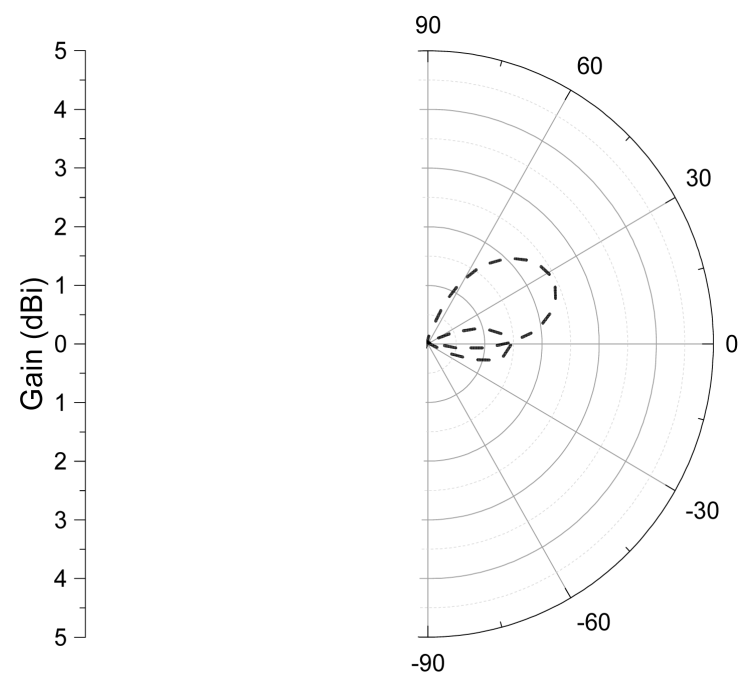

Radiation pattern at $7.71 \mathrm{GHz}$

(b)

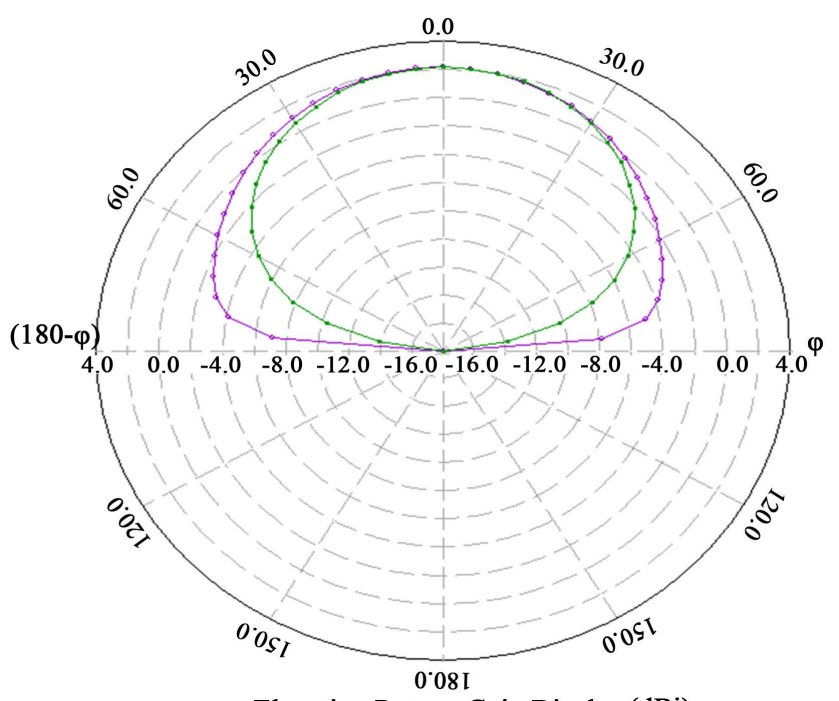

Elevation Pattern Gain Display (dBi)

(c) 


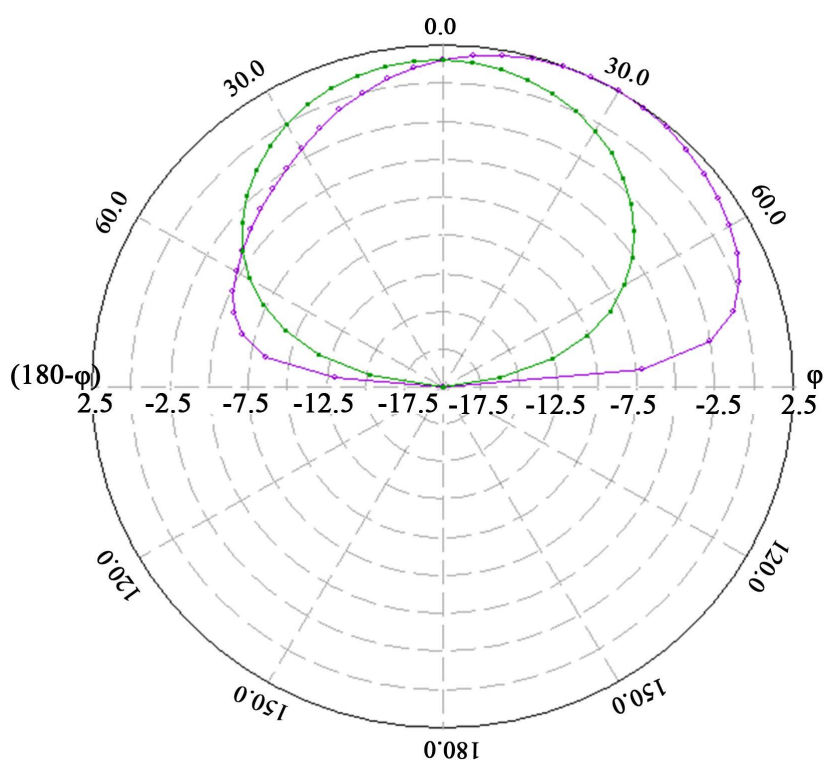

Elevation Pattern Gain Display (dBi)

(d)

Figures 7. Radiation patterns of the proposed antenna. (a) Radiation pattern in origin polar plot form of first band; (b) Radiation pattern in origin polar plot form of second band; (c) Polar plot radiation pattern at $4.42 \mathrm{GHz}$; (d) Polar plot radiation pattern at $7.74 \mathrm{GHz}$.

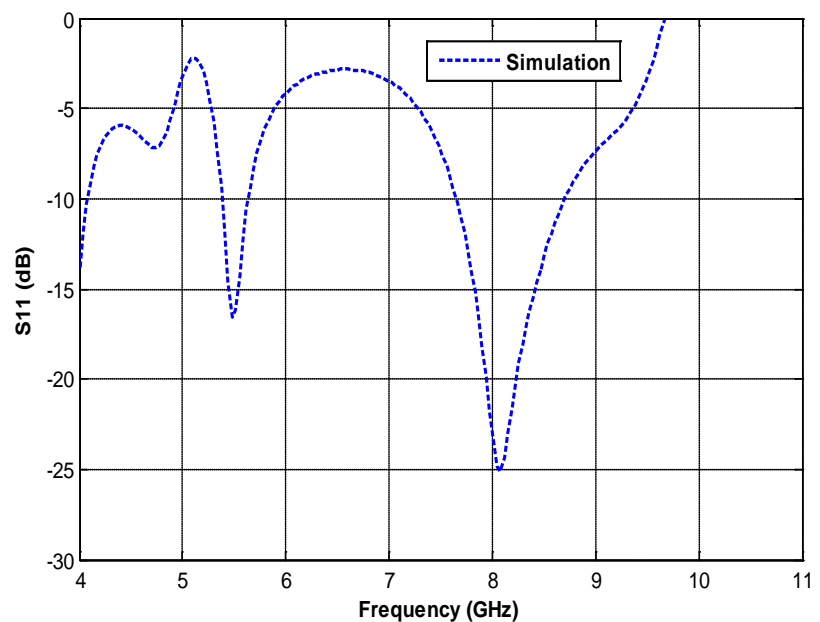

Figure 8. Variation of $\mathrm{S}_{11}$ parameter with frequency of the double parallel slots loaded circular disk.

If we used the double slots on circular disk patch the dual band antenna performance was found, which have already done in my previous work. The $S_{11}$ and gain variation of the dual band antenna is shown in Figure 8 and Figure 9. The radiation pattern of the dual band antenna is shown in Figure 10, which is not good as compared to other dual band antennas. And then think about single slot performance, which is shown in the next step.

Fourth step: In fourth step we used only single slot on circular disk and ground defected is same as earlier step. The dimensions for this design are listed in Table 1 and presentation is shown in Figure 11. The performance of single slot is like a single band antenna, which is the basic of the antenna.

\section{Simulated Results}

Figure 12 shows that the variation of simulated $\mathrm{S}_{11}$ results between single, double and triple slots loaded on cir- 


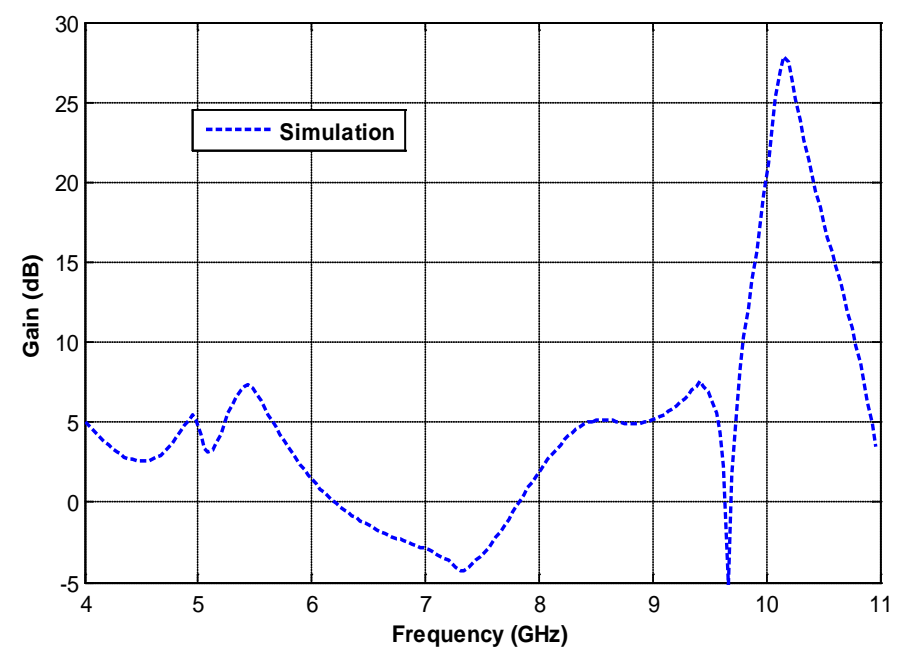

Figure 9. Variation of Gain with frequency of the double parallel slots loaded circular disk.
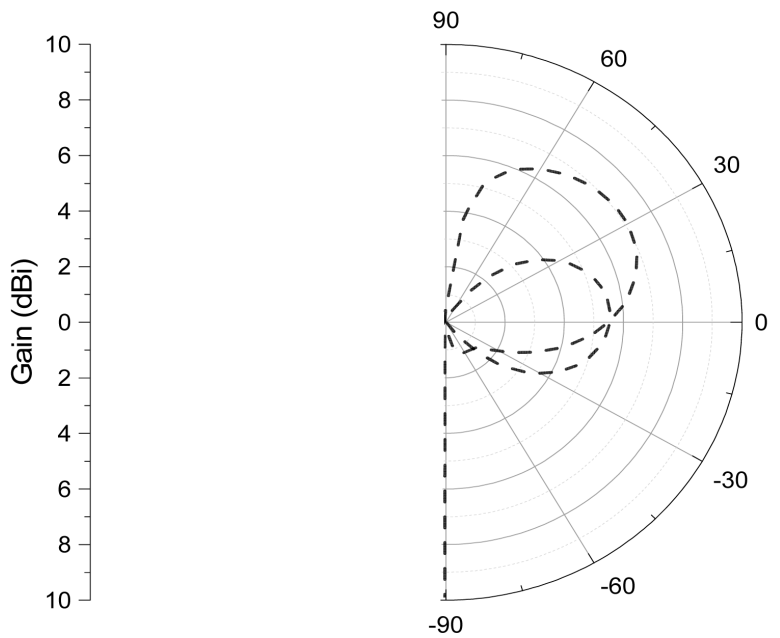

Radiation pattern at $5.48 \mathrm{GHz}$
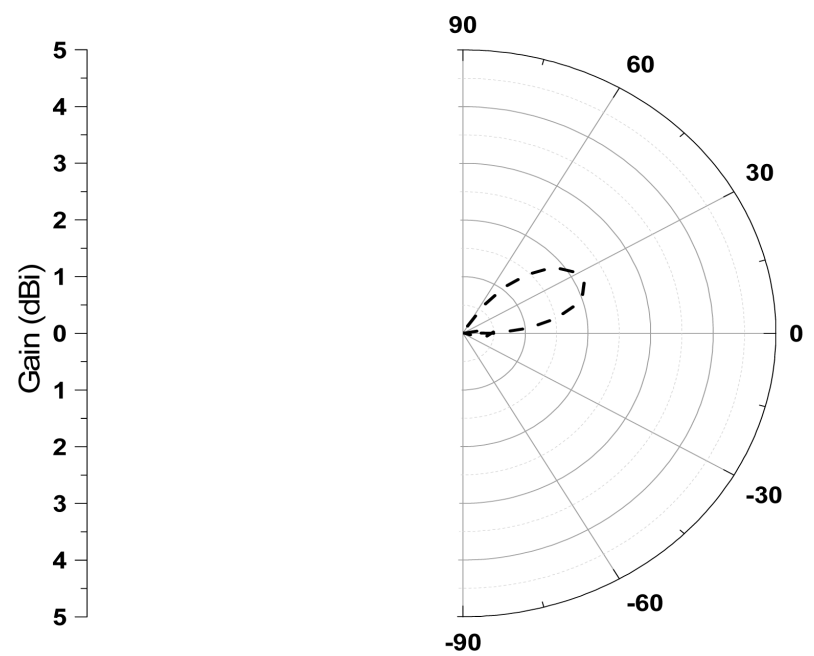

Radiation pattern at $8.06 \mathrm{GHz}$

Figure 10. Radiation pattern both $\mathrm{E}$ and $\mathrm{H}$ plane of double slots loaded circular disk patch. 


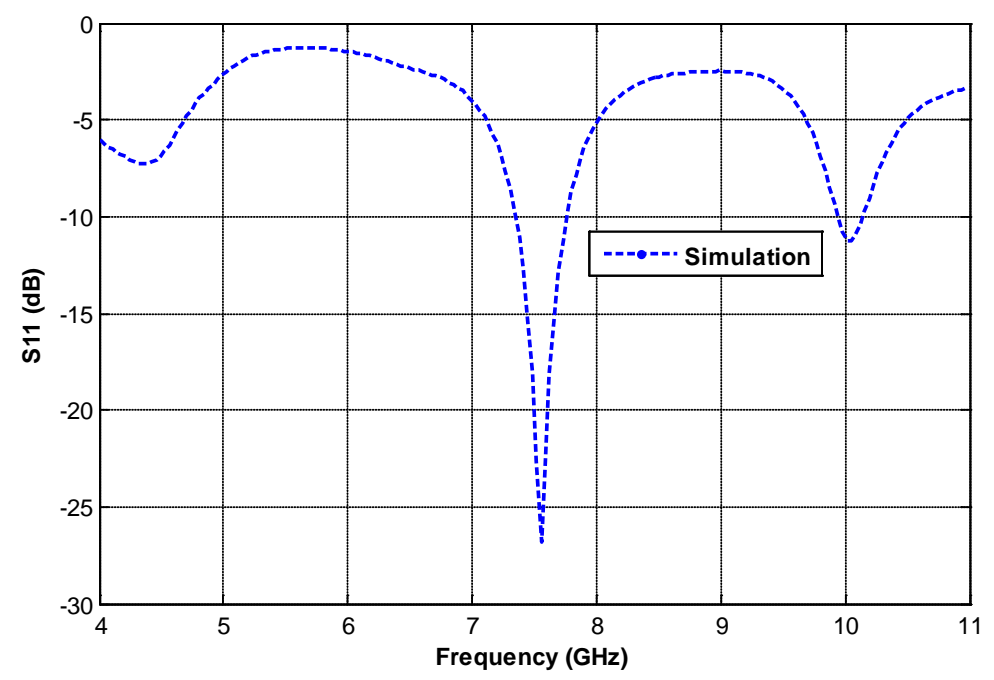

Figure 11. Variation of S11 parameter with frequency of the single slot loaded circular disk.

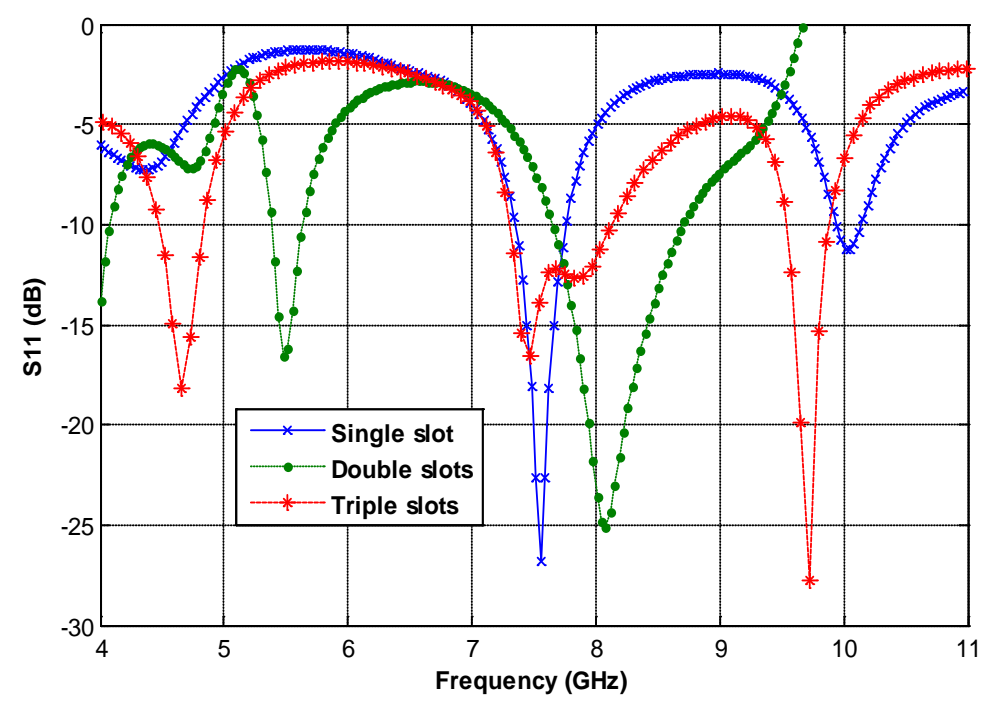

Figure 12. Variation of S11 parameter with frequency of the single, double and triple slot loaded antenna.

cular patch with defected ground plane. The simulated impedance bandwidths with $10 \mathrm{~dB}$ reflection coefficients of three different bands are $7.83 \%, 13.09 \%$ and $3.63 \%$ with gains, $2.30 \mathrm{dBi}, 3.61 \mathrm{dBi}$ and $0.67 \mathrm{dBi}$ respectively. This is only for three parallel slots loaded on circular patch, which is shown in Figure 12. If there are only two parallel slots with defected ground then the simulated impedance bandwidths with $10 \mathrm{~dB}$ reflection coefficients of two bands are $4.56 \%$ and $12.9 \%$ with high gain $7.26 \mathrm{dBi}$ at $4.45 \mathrm{GHz}$ and $27.8 \mathrm{dBi}$ at $10.16 \mathrm{GHz}$ respectively. Further if there is only single slot on circular patch with defected ground then the simulated impedance bandwidth with $10 \mathrm{~dB}$ reflection coefficients is $5.39 \%$ but gain is very low. It is clear that when we used three parallel slots on circular disk with defected ground, receiving the results tri-band and for double and single slots, we obtained dual and single band antenna respectively, which is already shown in above steps of design guidelines. In triple band antenna, first band can be used in ISM band/mobile communication application and other two bands can be used in radar systems. The gain of single band antenna is very low but due to double and triple slots loaded, the variation of antenna gains between them is shown in Figure 13. The simulated radiation patterns both in E-plane and H-plane at all the resonance frequencies are shown in above every steps of design guidelines which are reasonably in good conditions. 


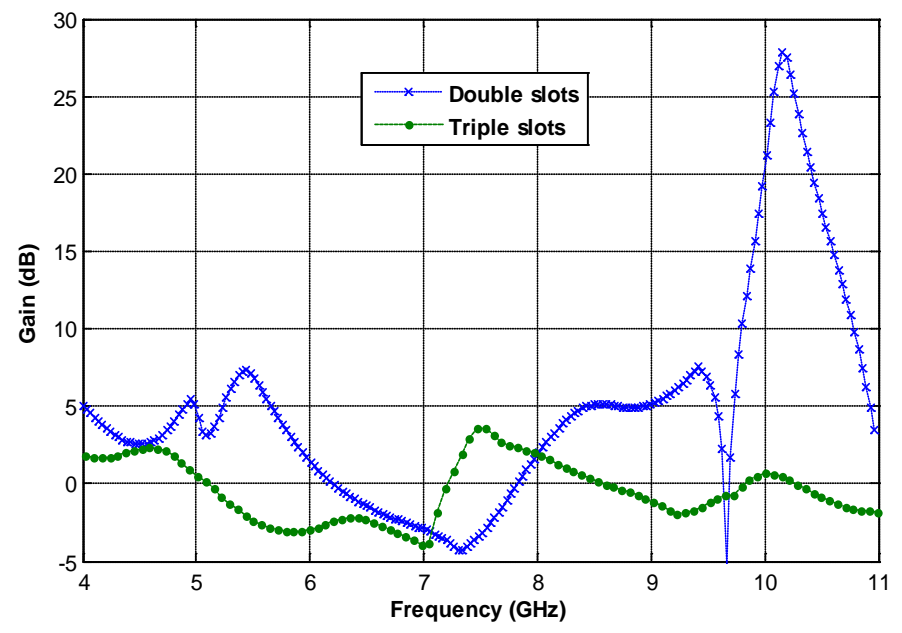

Figure 13. Variation of gain with frequency of the double and triple slot loaded antenna.

\section{Conclusion}

In this paper, a compact triple band circular disk antenna is realized by loading three parallel slots on circular disk and rectangular slot on the ground plane. The proposed antenna has impedance bandwidth covering the C-band (4.47 - 4.83 GHz, $7.30-8.13 \mathrm{GHz})$ and X-band $(9.53-9.89 \mathrm{GHz})$ frequencies. The design guidelines and appropriate equations are described and validated via IE3D simulations. The proposed antenna can be used in mobile applications.

\section{References}

[1] Arya, A.K., Kartikeyan, M.V. and Patnaik, A. (2010) Defected Ground Structure in the Perspective of Microstrip Antennas Review. Frequent International Journal of RF Engineering and Telecommunications, 64, 79-84.

[2] Li, H.Z. and Sun, X. (2005) Compact Defected Ground Structure in Microstrip Technology. Electronics Letters, 41, 132-134. http://dx.doi.org/10.1049/el:20057331

[3] Ansari, J.A., Mishra, A., Yadav, N.P. and Singh, P. (2010) Dual-Band Slot Loaded Circular Disk Patch Antenna for WLAN-Application. International Journal of Microwave and Optical Technology, 5, 124-129.

[4] Ansari, J.A., Mishra, A., Yadav, N.P., Singh, P. and Vishvakarma, B.R. (2013) Analysis of L-Shaped Slot Loaded Circular Disk Patch Antenna for Satellite and Radio Telecommunication. Wireless Persional Communication, 70, 927943.

[5] Cao, Y.F., Cheung, S.W. and Yuk, T.I. (2015) A Multiband Slot Antenna for GPS/WiMAX/WLAN System. IEEE Transactions on Antenna and Propagation, 63, 952-958.

[6] Prasad, D., Kumar, T., Satya, V.K., et al. (2011) Comparison of Circular and Rectangular Microstrip Patch Antennas. International Journal of Communication Engineering Application, 2, 187-197.

[7] Alkanhal, M.A.S. (2009) Composite Compact Triple-Band Microstrip Antennas. Progress in Electromagnetics Research, 93, 221-236. http://dx.doi.org/10.2528/PIER09050407

[8] Ysai, S.N., Hsin, H.H., Dia, H.K. and Cheng, K.T. (2002) Arcuate Slot Antenna. Assembly. US Patent No 6373443.

[9] Yogesh, B., Dinesh, Y., et al. (2010) V-Slotted Triangular Microstrip Patch Antenna. International Journal of Electronics Engineering, 2, 21-23.

[10] Akhavan, H.G. and Syahkal, D.M. (1999) Study of Coupled Slots Antennas Fed by Microstrip Lines. The 10th International Conferences on Antennas and Propagation, 1, 290-293.

[11] Anguera, J., Font, G., Puente, C, Borja, C. and Soler, J. (2003) Multifrequency Microstrip Patch Antenna Using Multiple Stacked Elements. IEEE Antenna and Wireless Components Letters, 13, 123-124. http://dx.doi.org/10.1109/LMWC.2003.810126

[12] Cao, Y., Yuan, B. and Wang, G. (2011) A Compact Multiband Open-Ended Slot Antenna for Mobile Handsets. IEEE Antenna and Wireless Propagation Letters, 10, 911-914.

[13] Jaheen, F. and Al Noman Ovi, A. (2013) Novel Design of Miniaturized Triple Band Square Microstrip Patch Antenna 
with F Slot for Fixed Service Satellite and Microwave C Band Applications. Progress in Electromagnetism Research Symposium Proceedings, Stockholm, 12-15 August 2013, 1429.

[14] Chen, H., Yang, X., Yin, Y.-Z., Wu J.-J. and Cai, Y.-M. (2013) Tri-Band Rectangle-Loaded Monopole Antenna with Inverted-L Slot for WLAN/WiMAX Applications. Electronics Letters, 49, 1261-1262.

http://dx.doi.org/10.1049/el.2013.2329

[15] Balanis, C.A. (2005) Antenna theory, Analysis and Design. 2nd Edition, John Wiley \& Sons, New York.

[16] Johnson, R.C. (1993) Antenna Engineering Handbook. 3rd Edition, MGH, Boston.

[17] Kumar, G. and Ray, K.P. (2003) Broadband Microstrip Antenna. Artech House, Baston, London, 184-187.

[18] Ray, K.P. and Kumar, G. (1999) Determination of Resonant Frequency of Microstrip Antennas. Microwave and Optical Technology Letters, 23, 114-117.

http://dx.doi.org/10.1002/(SICI)1098-2760(19991020)23:2<114::AID-MOP15>3.0.CO;2-G 